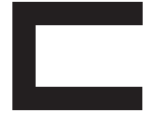

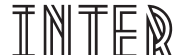

压(C医S

CIENTÍFICAS

EXATAS E TECNOLÓGICAS

ISSN IMPRESSO - 2359-4934

E- ISSN - 2359-4942

\title{
GOVERNANÇA DE TI: ANÁLISE DAS CONTRIBUIÇÕES DE MECANISMOS PRIVADOS NO GERENCIAMENTO PÚBLICO DE TI
}

\author{
IT GOVERNANCE: ANALYSIS OF CONTRIBUTIONS FROM PRIVATE MECHANISMS IN PUBLIC IT MANAGEMENT
}

GOBERNANZA DE TI: ANÁLISIS DE LAS CONTRIBUCIONES DE LOS MECANISMOS PRIVADOS EN LA GESTIÓN PÚBLICA DE TI

\section{RESUMO}

0 presente estudo, de natureza teórica, tem como objetivo analisar as contribuições dos mecanismos privados de governança de TI no gerenciamento público de TI, diante do contexto atual que demanda por eficiência, transparência, ética, prestação de contas e responsabilidade. Dentro deste propósito, construiu-se uma revisão teórica sustentada nos pilares e princípios das boas práticas de governança de corporativa e governança pública identificados na literatura nacional e internacional sobre Governança de TI. Os resultados mostram que mecanismos como os aplicados no Código de Governança
KING III, parâmetros administrativos baseados na Teoria da Agência, nos mecanismos da norma ISO 38500/2015 e frameworks para Governança de TI têm sido aplicados com sucesso e obtenção de bons, mas o Brasil ainda necessita avançar bastante na utilização dos mecanismos privados.

\section{PALAVRAS-CHAVE}

Governança de TI; Governança Pública; Gerenciamento Público de TI 


\section{ABSTRACT}

The present theoretical study aims to analyze the contributions of private IT governance mechanisms in public IT management, given the current context that demands efficiency, transparency, ethics, accountability and responsibility. Within this purpose, a theoretical review was built based on the pillars and principles of good corporate governance and public governance practices identified in the national and international literature on IT Governance. The results show that mechanisms such as those applied in the KING III Governance Code, administrative parameters based on the Agency Theory, the mechanisms of ISO $38500 / 2015$ and frameworks for IT Governance have been successfully applied and obtained good, but Brazil still need to make significant progress in the use of private mechanisms.

\section{KEYWORDS}

IT Governance; Public Governance; IT Public Management

\section{RESUMEN}

El presente estudio, de naturaleza teórica, tiene como objetivo analizar las contribuciones de los mecanismos privados de gobernanza de TI en la gestión pública de TI, ante el contexto actual que demanda por eficiencia, transparencia, ética, rendición de cuentas y responsabilidad. Dentro de este propósito, se construyó una revisión teórica sostenida en los pilares y principios de las buenas prácticas de gobierno corporativo y gobernanza pública identificados en la literatura nacional e internacional sobre Gobernanza de TI. Los resultados muestran que mecanismos como los aplicados en el Código de Gobernanza KING III, parámetros administrativos basados en la Teoría de la Agencia, en los mecanismos de la norma ISO 38500/2015 y frameworks para Gobernanza de TI se han aplicado con éxito y obtención de buenos, pero Brasil todavía necesita avanzar bastante en la utilización de los mecanismos privados.

\section{PALABRAS CLAVE}

Gobernanza de TI; Gobernanza Pública; Gestión de TI 


\section{INTRODUCÇÃO}

A Governança de Tecnologia da Informação (GTI) tem despertado um crescente interesse no meio acadêmico e nas organizações, refletindo a importância e a evolução da TI na sociedade contemporânea. "A Governança de Tecnologia da Informação (GTI) tem sido um dos dez temas mais importantes nas pautas das estratégias organizacionais e nas discussões entre os CIO's em todo o mundo", afirma Mahoney (2012, p. 28).

Em relação ao tema Governança de $\mathrm{Tl}$, a produção científica também tem aumentado de quantidade e importância nos últimos anos, como constata estudo bibliométrico realizado sobre o assunto que identificou 81 artigos publicados de 2007 a 2012 nos anais do Encontro Anual da Associação Nacional de Pós-graduação e Pesquisa em Administração - EnANPAD, do Encontro de Administração da Informação - EnADI e no portal Scientific Periodicals Library (SPELL), concluindo que o estudo da GTI no Brasil tem predominância ao alinhamento da TI aos negócios da empresa (MOTA; MARQUES, 2013, p. 7;12).

Dentro dessa perspectiva, a discussão envolve desde o tipo de tecnologia a ser adotada até definições de políticas e estratégias de como utilizar a TI para alavancar competitivamente as organizações, ao mesmo tempo em que é preciso dirigir e governar a TI para atender aos diferentes stakeholders, como recomendam as boas práticas de Governança Corporativa. No Setor Público, porém, existem lacunas que dificultam o uso de princípios de Governança Corporativa do Setor Privado como os descritos na New Public Management Theory (HOOD, 1995). Principalmente a inconsistência pela falta na Administração Pública de aspectos como lucro ou retorno de investimento, comuns ao setor privado, o que dificulta a comparação dos programas públicos, voltados para bem-estar dos cidadãos e legitimação das instituições políticas, enquanto o desempenho e a eficiência possuem a centralidade nas organizações privadas.

De maneira inicial, pode-se inferir que novos modelos de gestão pública, que foram adotados em vários países desde a década de 1980, estariam contribuindo para serem implantados nos órgãos públicos de TI os princípios da Governança de TI. No entanto, estudos dos Tribunais de Contas da União e Estaduais, dão conta que as fragilidades no setor público brasileiro denotam a falta da Governança de TI. A principal causa seria a ausência da boa Governança Corporativa e correspondente ausência de uma Gestão de TI. A dificuldade em estabelecer uma gestão pública adequada de TI é tida como uma decorrência da falta de Governança de TI nas Administrações Públicas (CAVALCANTI, 2008, p. 1; CRUZ, 2008, p. 12; BRASIL, 2017)

Esta pesquisa, considerando o contexto apresentado, busca responder às seguintes questões: os mecanismos privados de Governança de TI podem exercer melhor influência e produzir maiores contribuições para o gerenciamento público de TI? Quais elementos da Governança de TI estão inseridos nas novas formas de Gestão Pública de TI adotadas?

O propósito deste trabalho, de natureza teórica, é analisar as contribuições dos mecanismos privados de Governança de TI e sua aplicabilidade na administração pública, diante do contexto da atualidade que exige eficiência, transparência, responsabilidade, prestação de contas, ética e lisura nas ações da Administração Pública.

\section{FUNDAMENTAÇ̃̃O TEÓRICA}

\subsection{GOVERNANÇA}

A Governança no setor público se refere ao reconhecimento da importância da boa interação entre governo, sociedade civil e setor privado; trata de normas, regras e padrões de comportamento público aceitáveis por toda uma sociedade. Na atualidade, segundo Benedicto e outros autores (2013, p. 288) “[...] já existe um consenso de que não apenas organizações privadas devem adotar as práticas de governança, mas também os governos e instituições públicas".

\subsection{GOVERNANÇA CORPORATIVA}

O surgimento do conceito de Governança Corporativa está relacionado ao que alguns autores denomi- 
nam de conflito de agência. Estes conflitos aparecem quando um ou mais indivíduos contratam outra pessoa ou organização, denominados agentes (ou administradores), delegando-lhe a tomada de decisões. Estas decisões, entretanto, podem conflitar com os interesses dos acionistas, fazendo com que surja, então, o típico conflito de agência (RODRIGUES, 2010, p. 37-38)

Em função dos potenciais conflitos de agência existentes nas organizações, desponta o conceito de Governança Corporativa, como um conjunto de mecanismos de gestão, monitoração, controle e incentivo aos gestores, visando evitar ou minimizar os possíveis efeitos do conflito de agência. Para o Instituto Brasileiro de Governança Corporativa (IBGC, 2009, p. 19):

As boas práticas de governança corporativa convertem princípios em recomendações objetivas, alinhando interesses com a finalidade de preservar e otimizar o valor da organização, facilitando seu acesso ao capital e contribuindo para a sua longevidade.

Como princípios da Governança Corporativa, o IBGC (2009) define:

- Transparência - é o desejo de disponibilizar para as partes interessadas as informações que sejam de seu interesse e não apenas aquelas impostas por disposições de leis ou regulamentos;

- Equidade - tratamento justo de todos os sócios e demais partes interessadas (stakeholders);

- Prestação de contas (accountability) - os agentes de governança devem prestar contas de sua atuação, assumindo integralmente as consequências de seus atos e omissões;

- Responsabilidade Corporativa - zelar pela sustentabilidade das organizações, visando à sua longevidade, incorporando considerações de ordem social e ambiental na definição dos negócios e operações.

Para alinhar os interesses dos gestores aos dos acionistas, a governança corporativa prevê mecanismos internos com destaque para a atuação do Conselho de Administração, a proteção aos acionistas minoritários e incentivos aos gestores, e como mecanismos externos a obrigatoriedade de divulgação de informações periódicas sobre a empresa, a existência de um mercado de trabalho competitivo e a presença de um mercado de aquisição (amigável ou hostil).

Um exemplo prático de mecanismo de governança de TI é o estabelecimento de um processo transparente de tomada de decisão sobre a priorização de grandes demandas de TI. O gerenciamento de serviços de TI é, de fato, um enabler (facilitador) da governança de TI e esta é um facilitador da governança corporativa. Uma organização que faça uso intenso de TI, condição de grande parte das organizações que desejam ser eficientes hoje em dia, não pode afirmar ter uma boa governança corporativa sem ter boa governança de TI. Igualmente, a organização não pode afirmar ter uma boa governança de TI sem ter um bom gerenciamento de (serviços) de TI (BRASIL, 2014).

Para Korac-Kakabadse (2001), a Governança Corporativa está preocupada com a ação do conselho: seus papéis, sua composição, suas características, sua estrutura, e, ainda, com a estrutura e o processo organizacionais, de modo a desenvolver, implementar e acompanhar a estratégia corporativa. Dadas as suas características e definições, considera-se que a Governança de TI seja um subconjunto da Governança Corporativa (WEBB; POLLARD; RIDLEY, 2006; KORAC-KAKABADSE; KAKABADSE, 2001; ITGI, 2003).

\subsection{GOVERNANÇA DE TI}

A Governança de TI tem foco no direcionamento e monitoramento das práticas de gestão e uso da TI de uma organização, tendo como indutor e principal beneficiário a alta administração da instituição (BRASIL, 2014). Weill e Ross (2004 apud FERNANDES; ABREU, 2012, p. 12), entendem a Governança de TI como "[...] um ferramental para a especificação dos direitos de decisão e responsabilidade, visando encorajar comportamentos desejáveis no uso da TI”. A Governança de TI busca o direcionamento da TI para atender ao negócio e o monitoramento para verificar a conformidade com o direcionamento tomado pela administração da organização (FERNANDES; ABREU, 2012, p. 13). 
Como constatado pelo Tribunal de Contas da União (CAVALCANTI, 2008; CRUZ, 2008; CEPIK; CANABARRO, 2010), as fragilidades no setor público brasileiro denotam a falta da Governança de Tle a principal causa seria a ausência da boa Governança Corporativa. A ausência de uma Gestão de TI adequada no setor público é demonstrada por alguns indicadores, conforme Rodrigues (2010, p. 15) aponta:

\footnotetext{
- precariedade na definição de diretrizes estratégicas; - falta de alocação de recursos humanos, materiais e financeiros para adequadamente cumprir as metas de TI; e,

- precariedade dos controles sobre os processos de TI, que acontecem dentro e fora das áreas de TI.
}

A dificuldade em estabelecer uma gestão adequada de TI pode ser percebida como decorrência da falta de entendimento sobre o conceito de Governança de TI por parte dos profissionais de TI. Segundo Rodrigues (2010, p. 26), esta falta de clareza sobre o conceito Governança de TI não surpreende, pois Sistemas de Informação é uma disciplina relativamente nova, em que a maioria dos autores que a definem empregam seu sentido, dependendo do objetivo do pesquisador e da pesquisa.

Quando é realizada uma discussão sobre Governança de TI logo se faz necessário analisar quais são os frameworksque continuam se atualizando conforme o mercado se atualiza também. Não é de muito conhecimento um passo a passo orientando as organizações no que devem fazer para se ter uma governança eficaz em TI. Porém, estudando e implementando de forma gradativa as melhores práticas que esses frameworks propõem, haverá uma melhora considerável em todos os níveis hierárquicos: no estratégico, no tático e no operacional. Os frameworks mais referenciados são o COBIT e o ITIL, analisados a seguir.

\subsection{PRINCIPAIS FRAMEWORKSPARA GOVERNANCWA DE TI: COBITEITIL}

Com o objetivo de facilitar o alinhamento estratégico entre a Tl e a alta administração das organizações, recentemente têm sido criados e adaptados frameworks de boas práticas em gestão da TI como o Control Objectives for Information and Related Tech- nology (COBIT). O COBIT concentra-se na definição, implementação, fiscalização, medição e melhoria dos controles para processos específicos, que abrangem toda a implementação do ciclo de vida da TI, é um excelente modelo de referência para governança de TI.

Em 2012, foi lançado pelo ISACA a versão 5 do modelo de maturidade COBIT. Segundo Souza Neto e Santos (2012) está baseado no método de avaliação da organização e pode ser calculado a partir do nível de maturidade inexistente (0) a otimizado (5), facilitando o trabalho dos gerentes TI. A escala inclui 0 porque é possível que o processo não exista.

A partir dessa escala genérica é descrito um modelo específico para cada um dos processos dentro dos 4 domínios que compõem o COBIT: Planejamento e Organização; Aquisição e Implementação; Entrega e Suporte; e Monitoração. No domínio Planejamento/Organização, por meio do Processo 01 determina a Elaboração do Planejamento Estratégico de TI (PETI). Este, por sua vez, dirige a elaboração do Plano Diretor de TI (PDTI).

O PDTI é um documento de planejamento que se tornou obrigatório na administração pública federal desde 2010, a partir da Instrução Normativa SLTI 04/2010, que vincula toda contratação de TI com alguma ação prevista no PDTI. No âmbito da administração federal, anualmente a Controladoria Geral da União (CGU) realiza auditoria nos órgãos federais onde um dos itens analisados é a existência de planejamentos de TI: o PETI que define as estratégias gerais de TI e o PDTI que desdobra essas estratégias em ações, ou seja, o planejamento tático.

A elaboração de um PDTI proporciona um rico conjunto de questionamentos, reflexões e revisionamentos que produzirão um amadurecimento da TI e da própria organização. Podem ser citados, dentre os benefícios esperados, de acordo com Oikawa, Chaves e Galegale (2013, p. 6):

- Reflexões sobre a missão e visão de futuro da unidade de TI, alinhadas à missão e visão de futuro da instituição;

- Busca de respostas às oportunidades e ameaças externas e aos pontos fracos e fortes internos, de modo a cumprir suas atribuições com efetividade;

- Identificação, revisão e explicitação dos objetivos, orientações estratégicas e recomendações para a 
TI corporativa, alinhados aos objetivos e orientações estratégicas na organização, e os decorrentes planos de ação atrelados às necessidades das áreas de negócio;

- Identificação e explicitação não apenas das ações operacionais a serem realizadas pela área de TI, mas também dos aspectos de estrutura e gestão sobre a TI corporativa, em especial pela operacionalização de uma estrutura de governança que viabilizará a execução das ações e a revisão periódica do PDTI aprovado;

- Desenvolvimento de capacidades individuais que fortaleçam e assegurem a execução dos planos e projetos de TI.

O COBIT é, portanto, um guia para a gestão de TI, utilizado como um modelo para gestão que abrange o nível estratégico, tático e uma parte do operacional. Por sua vez, o Information Technology Infrastructure Library (ITIL) abrange o nível operacional e uma parte do tático (SANTOS; PAULA, 2016).

Surgido na década de 1980, em função da insatisfação do governo Britânico na qualidade do serviço de TI prestado, o ITIL está em sua versão atual de 2011. Tem por objetivo gerenciar os serviços de TI e guiar as organizações para definirem qual a melhor maneira de executar um determinado processo. O ITIL tem como foco principal, a operação e a gestão da infraestrutura de tecnologia na organização, incluindo todos os assuntos que são importantes no fornecimento dos serviços de TI. Este framework orienta a existência de ciclos de vida na execução do serviço a ser efetuado, no qual existe um conjunto de 5 fases que constituirão a gestão de serviços: Estratégia, Desenho, Transição, Operação e Melhoria Continua.

Na sua implementação para execução da Governança de TI, em primeiro lugar é fundamental alinhar os objetivos da organização com os objetivos da área de TI, conforme trata a fase 1 - Estratégia, com a explícita intenção de implementar um programa de melhoria continua de serviços. Prosseguindo com a aplicação das fases, como segunda etapa, a fase 2 - Desenho, é necessária uma avaliação da situação atual em termos de direcionamento do negócio e investimento; na fase 3 - Transição, elaborar uma perspectiva realista do nível de maturidade alinha- da ao framework ITIL e qualidade de serviço prestada; na fase 4 - Operação, executar com nítida visão da área de TI sobre o que esperam os responsáveis da organização e vice-versa. Por fim, um estabelecimento de metas e objetivos onde se deseja chegar, com verificações periódicas que formem um ciclo, proporcionando a melhoria continua da fase 5 (SANTOS; PAULA, 2016).

Qualquer que seja o tipo de organização, privada ou pública, a necessidade de Governança Corporativa e de TI é entendida como primordial. Este reconhecimento torna necessário analisar os códigos de governança elaborados nacional e internacionalmente com o propósito de identificar os mecanismos de GTI que apresentam.

\subsection{MECANISMOS PRIVADOS DE GTI: REFERÊNCIA CÓDIGOS GOVERNANÇA CORPORATIVA DA ÁFRICA DO SUL KING III}

Conforme cresce a percepção das organizações sobre a TI não ser mais apenas uma facilitadora de operações, mas uma parte constitutiva do negócio, determinante no apoio, sustentação e crescimento da organização, aumenta a importância da Governança de TI junto a Governança Corporativa. Nesta perspectiva, em meio aos Códigos de Governança Corporativa elaborados internacionalmente, o Código de Governança Princípios para a África do Sul, nomeado modelo King III (IODSA, 2009), é o primeiro a destacar princípios de Governança de TI a serem observados dentro da Governança Corporativa (MASSON et al., 2014).

A partir da análise de alguns dos principais códigos de governança corporativa como Financial Reporting Council (FRC, 2014) do Reino Unido, o OECD (2004), transnacional, o IBGC (2009) do Brasil, o modelo de Weill e Ross (2006), e o Institute of Directors Southern Africa (IODSA, 2009), conhecido como modelo King III, constata-se que o modelo de Weill e Ross é o primeiro a fazer referência aos ativos de informação e de TI como aspectos da governança corporativa, porém o modelo King III é o único a destacar princípios de Governança de TI a serem observados dentro da Governança Corporativa (MASSON et al., 2014).

O Código de Governança Corporativa KING III (IOSDA, 2009) é resultado do trabalho iniciado em 1994 realizado 
pelo King Comittee on Corporate Governance e ganhou na sua última revisão destaque e reconhecimento internacional, colocando a África do Sul em condição de destaque no campo da Governança Corporativa. A filosofia do King III define que uma boa governança corporativa deve estar baseada em torno de princípios como liderança, sustentabilidade e cidadania corporativa. (IOSDA, 2009, p. 10).

Com a evolução da Internet, do comércio eletrônico e da comunicação eletrônica as empresas passaram a realizar negócios eletronicamente por meio de transações em tempo real. Esta realidade trouxe riscos significativos que, somados aos grandes investimentos em projetos de TI, apontam para a necessidade de regulação e controle (IOSDA, 2009, p. 11). Não é diferente o tratamento para projetos de TI destinado ao Setor Público. A não existência de lucro ou retorno sobre investimento abre espaço para transparência e benefício ao contribuinte.

Deste modo, deve ser dada atenção para a integridade e disponibilidade do funcionamento dos sistemas de informação; para as propriedades destes sistemas; para a autenticidade da informação e o retorno de investimento dos projetos de TI. Assim sendo, com a percepção de que a Tl é fator crítico na Governança Corporativa, o King III tornou-se o primeiro Código de Governança Corporativa a abordar a Governança de TI em detalhes.

A seguir são descritos os princípios, segundo o King III, referentes à TI, presentes no Capítulo 5 do Código de Governança (IOSDA, 2009, p. 39-40):

Quadro 1 - $5^{0}$ Princípio - Governança de Tecnologia da Informação

\begin{tabular}{|c|c|}
\hline Princípio & Práticas Recomendadas \\
\hline $\begin{array}{l}5.10 \text { Conselho de } \\
\text { Administração ou similar } \\
\text { deve ser responsável pela } \\
\text { Governança de TI }\end{array}$ & $\begin{array}{l}\text { 5.1.1. O conselho deve assumir a responsabilidade para a governança de TI e } \\
\text { controlar a agenda de sua execução. } \\
\text { 5.1.2. O conselho deve assegurar que exista um Comitê de TI e acompanhar como } \\
\text { as políticas de TI são estabelecidas e implementadas. } \\
\text { 5.1.3. O conselho deve assegurar a promoção de uma cultura de governança de TI } \\
\text { ética e responsável, e uma linguagem comum de TI. } \\
\text { 5.1.4. O conselho deve assegurar a adoção de uma estrutura interna de controle da TI. } \\
\text { 5.1.5. O conselho deve receber avaliações independente sobre a eficácia dos } \\
\text { controles internos da TI. }\end{array}$ \\
\hline $\begin{array}{l}\text { 5.2. A TI deve estar } \\
\text { alinhada com o } \\
\text { desempenho e objetivos } \\
\text { de sustentabilidade da } \\
\text { empresa. }\end{array}$ & $\begin{array}{l}\text { 5.2.1. O conselho deve garantir que a estratégia de TI é integrada com processos } \\
\text { estratégicos e de negócio da empresa. } \\
\text { 5.2.2. O conselho deve garantir que haja um processo para a identidade e explorar } \\
\text { as oportunidades para melhorar o desempenho ea sustentabilidade da empresa } \\
\text { através do uso de TI. }\end{array}$ \\
\hline $\begin{array}{l}\text { 5.3. O Conselho de } \\
\text { Administração deve } \\
\text { delegar à direção executiva } \\
\text { a responsabilidade pela } \\
\text { implementação de um } \\
\text { framework de Governança } \\
\text { de TI }\end{array}$ & $\begin{array}{l}\text { 5.3.1. A administração de TI deve ser responsável pela execução das estruturas, } \\
\text { processos e mecanismos de governança de TI. } \\
\text { 5.3.2. O conselho poderá nomear um comitê gestor de TI para ajudar com sua } \\
\text { governança de TI. } \\
\text { 5.3.3. O CEO deve nomear um Chief Information Officer }(\mathrm{CIO}) \text { responsável pela } \\
\text { gestão de TI. } \\
\text { 5.3.4. O CIO deve ser um profissional devidamente qualificado e experiente, que } \\
\text { deve ter acesso e poder interagir regularmente em assuntos estratégicos de TI com } \\
\text { a diretoria e/ou comitê gestor de TI e gestão executiva. }\end{array}$ \\
\hline
\end{tabular}


Quadro 1 - $5^{\circ}$ Princípio - Governança de Tecnologia da Informação (Continuação)

\begin{tabular}{|c|c|}
\hline Princípio & Práticas Recomendadas \\
\hline $\begin{array}{l}\text { 5.4. O Conselho de } \\
\text { Administração deve } \\
\text { monitorar e avaliar in- } \\
\text { vestimentos e despesas } \\
\text { significativos em TI }\end{array}$ & $\begin{array}{l}\text { 5.4.1. O conselho deve supervisionar a entrega de valor de TI e monitorar o retorno } \\
\text { sobre o investimento a partir de projetos de TI significativos. } \\
\text { 5.4.2. O conselho deve assegurar que a propriedade intelectual contida em sistemas } \\
\text { de informação são protegidos. } \\
\text { 5.4.3. O conselho deve obter uma garantia independente sobre a governança de TI e } \\
\text { controles de suporte a serviços de TI terceirizados. }\end{array}$ \\
\hline $\begin{array}{l}\text { 5.5. A TI deve fazer } \\
\text { parte integral da gestão } \\
\text { de riscos da empresa }\end{array}$ & $\begin{array}{l}\text { 5.5.1. A administração de TI deve demonstrar regularmente ao conselho que a empre- } \\
\text { sa tem acordos de resiliência de negócios adequados no local para recuperação de } \\
\text { ativos em caso de desastres. } \\
\text { 5.5.2. O conselho deve garantir que a empresa está em conformidade com as leis e que } \\
\text { regras, códigos e normas são respeitados. }\end{array}$ \\
\hline $\begin{array}{l}\text { 5.6. O Conselho de } \\
\text { Administração deve as- } \\
\text { segurar que os ativos de } \\
\text { informação são geridos } \\
\text { de forma eficaz. }\end{array}$ & $\begin{array}{l}\text { 5.6.1. O conselho deve assegurar a existência de sistemas adequados para a gestão } \\
\text { da informação que deverá incluir informações de segurança, gestão da informação e } \\
\text { privacidade da informação. } \\
\text { 5.6.2. O conselho deve assegurar que todas as informações pessoais serão tratados } \\
\text { pela empresa como um importante ativo de negócios. } \\
\text { 5.6.3. O conselho deve assegurar que um Sistema de Gestão de Segurança da Informa- } \\
\text { ção é desenvolvido e implementado. } \\
\text { 5.6.4. O conselho deve aprovar a estratégia de segurança da informação e capacitar a } \\
\text { gestão para implementar a estratégia }\end{array}$ \\
\hline $\begin{array}{l}\text { 5.7. Um comitê de } \\
\text { risco e um comitê de } \\
\text { auditoria devem auxiliar } \\
\text { o Conselho no cumpri- } \\
\text { mento de suas respon- } \\
\text { sabilidades relaciona- } \\
\text { das a TI }\end{array}$ & $\begin{array}{l}\text { 5.7.1. O comitê de risco deve assegurar que os riscos de TI são tratados de forma adequada. } \\
\text { 5.7.2. O comitê de risco deve obter garantias adequadas de que os controles estão no } \\
\text { local e são eficazes na abordagem de riscos de TI. } \\
\text { 5.7.3. O comitê de auditoria deve considerar como o risco influencia nos relatórios } \\
\text { financeiros, deve ser preocupação constante da empresa. } \\
\text { 5.7.4. O comitê de auditoria deve considerar o uso da tecnologia para melhorar o } \\
\text { alcance da auditoria e sua eficiência. }\end{array}$ \\
\hline
\end{tabular}

Fonte: IOSDA (2009).

Em $1^{\circ}$ de Novembro de 2016, foi lançado o King Report IV com atualizações que não afetaram profundamente $05^{\circ}$ princípio da Governança de TI.

\section{PROCEDIMENTOS METODOLÓGICOS}

O presente estudo é uma pesquisa bibliográfica que trata da adoção de mecanismos privados de Governança de TI no gerenciamento público de TI, buscando identificar contribuições destes mecanismos na Gover- 
nança de TI no Setor Público. A pesquisa bibliográfica consiste em relatar um problema com base apenas em informações coletadas de referências relacionadas ao tema e produzidas por autores relevantes. Para realização da pesquisa, inicialmente foram realizados levantamentos bibliográficos que tinham o propósito compreender para futura análise o tema proposto, por meio de artigos, livros, casos de estudo sobre a adoção da Governança de TI no setor público e privado.

Após a busca pelos artigos, livros e casos de estudo nas principais plataformas de periódicos e bases de consulta bibliográfica da área temática, foi realizada a sua leitura e análise para identificação das contribuições conforme os principais conceitos tratados neste estudo.

\section{RESULTADOS}

Nesta seção estão contidas as análises da literatura nacional e internacional estudada sobre os mecanismos privados de Governança de TI e suas contribuições para o setor público. No Quadro 2, a seguir, estão organizados os autores e trabalhos mais relevantes com os seus respectivos mecanismos privados de Governança de TI indicados:

Quadro 2 - Autores relevantes e mecanismos privados de Governança de TI

\begin{tabular}{|l|l|}
\hline Autor (Ano) & Mecanismos Privados de Governança de TI \\
\hline Masson et al (2014) & $\begin{array}{l}\text { Conselho de Administração deve ser responsável pela Governança de TI; deve delegar } \\
\text { à direção executiva a responsabilidade pela implementação de um framework de GTI; } \\
\text { deve monitorar e avaliar investimentos e despesas significativos em TI; a TI deve estar } \\
\text { alinhada com o desempenho e objetivos de sustentabilidade da empresa; um comitê } \\
\text { de riscos e um comitê de auditoria devem auxiliar o Conselho no cumprimento de suas } \\
\text { responsabilidades. }\end{array}$ \\
\hline Medeiros et al (2016) & $\begin{array}{l}\text { Nível de Capacidade dos Processos de TI; Liderança sobre a área de TI; Estratégias e } \\
\text { Planos Adotados pela área de TI; Informações e Conhecimento da área de Tl; Quantida- } \\
\text { de e Capacitação dos servidores da área de TI; Transparência Resultados da área de TI; } \\
\text { Orçamento da área de TI. }\end{array}$ \\
\hline Dawson et al (2016) & $\begin{array}{l}\text { Comitê Legislativo de Supervisão; Escritório Independente do Chefe de Executivo de TI; } \\
\text { Fundo Livres para serviços de TI; }\end{array}$ \\
\hline Santos; Paula (2016) & $\begin{array}{l}\text { Forte alinhamento entre negócios e estratégias de TI, através da coerência de domí- } \\
\text { nios e processos do COBIT; Criação de processos definidos com estruturas internacio- } \\
\text { nalmente aceitas, auditáveis e mensuráveis; Identificação de métricas para garantir o } \\
\text { controle interno de Tl; Quebra de barreiras e paradigmas em relação uso da TI na orga- } \\
\text { nização. }\end{array}$ \\
\hline Dolci; Maçada (2013) & $\begin{array}{l}\text { Governança contratual: contratos, poder, incentivos, coordenação e controle; Gover- } \\
\text { nança relacional: relacionamento, flexibilidade, qualificação, capacidade, veracidade, } \\
\text { integração, comprometimento, colaboração e cooperação; Governança transacional: } \\
\text { custo, complexidade, codificação e oportunidade; Transparência nas relações; Investi- } \\
\text { mento em TI. }\end{array}$ \\
\hline Santos; Santos Jr (2017) & $\begin{array}{l}\text { Suporte da alta administração; atuação do comitê de direção de TI; utilização do plane- } \\
\text { jamento estratégico de TI, atuação da gestão de portfólio de investimentos de TI. }\end{array}$ \\
\hline
\end{tabular}

Fonte: Elaborado pelo autor da pesquisa. 
No cenário nacional, é possível verificar a existência de pesquisas com foco no gerenciamento público de TI, que apontam ser reconhecido já há bastante tempo à efetiva importância da Governança de TI para o sucesso das organizações do setor público e quais mecanismos são necessários para o alcance de resultados compatíveis com as expetativas da sociedade (MEDEIROS et al., 2016, SANTOS; PAULA, 2016, DOLCI; MAÇADA, 2013, SANTOS; SANTOS JR., 2017). Porém, existem poucas pesquisas para medir quais mecanismos contribuem no estabelecimento desta efetividade dentro das organizações do setor público.

Um dos componentes principais da Governança de TI no setor privado, o conselho de administração, não existe no setor público. Em sua pesquisa, Dawson e outros autores (2016) examinam a eficiência da Governança de TI no Setor Público, utilizando a visão legal da Teoria da Agência. No estudo, baseado no setor público dos Estados Unidos da América (USA) esses autores evidenciam que a inexistência do conselho de administração dificulta o gerenciamento da distribuição dos recursos estatais. Estes autores identificaram, ainda que, nos Estados, onde foram aplicados os conceitos da Teoria da Agência e implantados conselhos de direção para a gestão solidária da hierarquia de tomada de decisões sobre TI a melhora na gestão dos recursos públicos.

Dawson e outros autores (2016) observam também que a criação de escritórios, independentes de chefes de informação, juntamente com fundos livres para serviços geraram um desempenho superior na gestão pública de $\mathrm{TI}$, com ganhos superiores a $40 \%$ de retorno dos recursos investidos em $\mathrm{Tl}$, superando o desempenho dos tradicionais departamentos públicos de TI. Os autores apontam que a mudança de controle dos recursos, saindo de um modelo estritamente gerido pela visão do governo para um com maior participação da sociedade civil, por meio de mecanismos privados, permitiu um atendimento com melhor resultado, melhor performance, por meio dos comitês legislativos de supervisão. Estes comitês funcionam de forma idêntica aos Conselhos de Administração na Governança de TI do Setor Privado.
Os mecanismos apresentados no modelo King III no estudo de Masson e outros autores (2014) são apropriadamente utilizados pela Governança de TI, analisada no estudo de Dawson e outros autores (2016). Ao direcionar a responsabilidade pela Governança de TI como uma atribuição dos comitês legislativos de supervisão, o mecanismo privado funciona como auxiliar na gestão de riscos e, a auditoria fica estabelecida pelos escritórios independentes do chefe executivo de TI.

Entretanto, por meio da literatura referente à Governança de TI no setor privado, podem ser identificados aspectos semelhantes e divergentes da aplicação do seu conceito no setor público, o que permite traçar um paralelo entre os modelos. De acordo com Rodrigues (2010), recebem destaque alguns mecanismos basilares nas organizações que governam sua TI: alinhamento estratégico entre a TI e os negócios, entrega de valor pela $\mathrm{TI}$ à organização, gerenciamento do desempenho da TI, gerenciamento dos riscos relacionados a TI, gerenciamento dos recursos e responsabilização pelas decisões de TI (RODRIGUES, 2010).

Com base nos mecanismos vistos na literatura, é possível discutir a sua relação e contribuições com o Gerenciamento Público de TI:

- No alinhamento estratégico entre a TI e os negócios: o departamento público de TI não pode desconhecer os objetivos estratégicos, nas organizações públicas ou privadas, como é possível observar a existência de departamentos com esse comportamento nas diversas esferas da administração pública nacional. É de fundamental importância, para que seja obtido suporte nas ações presentes e futuras, a existência de um alinhamento entre a TI e os negócios no gerenciamento público de TI (MASSON et al., 2014; MEDEIROS et al., 2016, SANTOS; PAULA, 2016, DAWSON et al., 2016, SANTOS; SANTOS JR., 2017);

- No Gerenciamento dos riscos inerentes a TI, no Gerenciamento de Recursos, no Controle, no Gerenciamento do Desempenho e na responsabilização pelas decisões de TI: não existe diferenciação entre os resultados esperados nas organizações públicas 
daqueles, percebidos nas organizações privadas. A busca no setor privado pelo resultado é equivalente no setor público à busca pela conformidade (MASSON et al., 2014; SANTOS; PAULA, 2016);

- Na Entrega de Valor pela TI à organização: em sua agregação de valor não estão envolvidos, necessariamente, aspectos financeiros. A área de TI, ou departamento público de TI, deve buscar resultados e desempenho, de forma direta ou indireta, para o atingimento das metas da organização, quer seja pública ou privada (MASSON et al., 2014; DOLCI; MAÇADA, 2013, SANTOS; SANTOS JR., 2017)

Para o setor público, a falta de competitividade explica o fato de apresentar atrasos no desenvolvimento e aplicação da TI em relação ao Setor Privado. Ainda assim o setor público sofre com as influências do ambiente político, com foco nos seus próprios interesses (conflito de agência), dos sistemas de valores, que proporcionam discussão sobre questões éticas, ainda, cumprimento de normas e dispositivos. A área de TI, no setor público ou privado, sofre de pressões institucionais internas e externas.

Sem sombra de dúvida, estas pressões institucionais produzem fortes demandas para as áreas de TI no setor público e as pressões financeiras e do mercado, são as forças propulsoras no setor privado. A diferença está na forma como os agentes responsáveis pela Governança de TI reagem às pressões. A reação no setor privado está concentrada na reversão do resultado financeiro, no retorno do capital investido, na sobrevivência da empresa. Para o setor público, o objetivo é salvaguardar as decisões, legitimar as ações, a sobrevivência da organização depende do cumprimento de cerimoniais, mitos culturais e ritos legais, tendo em vista a inexistência de indicadores financeiros de resultado.

\section{CONSIDERACÕ̃ES FINAIS}

Este trabalho teve como objetivo analisar, à luz de diversos autores, as contribuições dos mecanis- mos privados de Governança de TI no Gerenciamento Público de $\mathrm{TI}$, diante do contexto da atualidade que demanda por eficiência, transparência, ética, responsabilidade, lisura nas ações e prestação de contas à sociedade pelos órgãos do setor público.

Assim, foram investigados os conceitos relativos aos mecanismos privados de Governança de TI e como primeiro resultado ficou demonstrada, por meio da análise da literatura nacional e internacional, a contribuição destes mecanismos como adequadamente utilizáveis no gerenciamento público de TI. Não é de se esperar que exista diferença alguma no resultado dos departamentos públicos de TI frente aos setores privados, a despeito de não objetivarem lucro ou resultado financeiro, mas tendo em vista a sua obrigatoriedade de alcance da conformidade legal e do atendimento à sociedade.

Em segundo lugar, ao analisar as contribuições dos mecanismos privados, por meio da apresentação dos Comitês de Supervisão Legislativa na Gestão Pública de TI nos EUA e seu desempenho superior por meio da gestão do modelo de Fundos de Taxas de Serviços, junto com os Escritórios de Independentes de Chefes de Informação, ficou evidente a contribuição favorável do mecanismo de Conselho de Administração do Setor Privado. Com a aplicação dos mecanismos de alinhamento estratégico da TI ao negócio, responsabilidade, desempenho, entrega de valor pela TI à organização, as contribuições foram benéficas para os estados que adotaram os conceitos da Teoria da Agência no suporte à Governança Pública de TI.

Por fim, na aplicação do código de Governança King III é possível encontrar um roteiro efetivo de condução das ações de Governança de TI aplicável ao setor público e privado, de forma a contemplar os princípios da norma ISO/IEC 38500, bem como direcionar investigações futuras sobre a forma como a Administração Pública Brasileira, em quaisquer das suas esferas, poderia reconhecer o seu estado atual de desenvolvimento em relação aos modelos nacionais e internacionais que são aplicados no Gerenciamento Público de TI. 


\section{REFERÊNCIAS}

BENEDICTO, S.C. de et al. Governança corporativa: uma análise da aplicabilidade dos seus conceitos na administração pública. Organizações Rurais e Agroindustriais, Lavras, v.15, n.2, p.286-300, 2013.

BRASIL. Tribunal de Contas da União. Acórdão 786/2006-TCU-Plenário. 2006. Disponível em: <http://contas.tcu.gov.br/portaltextual/MostraDoc umento?lnk=(acordao+adj+786/2006+adj+plenario) [idtd][b001]>. Acesso em: 31 jul. 2014.

CAVALCANTI, Augusto Sherman. As principais deliberações do TCU sobre Tecnologia da Informação. 2008. Disponível em <http://portal2.tcu.gov.br/ portal/page/portal/TCU/comunidades/tecnologia_ informacao/sefti_eventos/apresentacoes/2008/02 Discurso_Min_ASC_Seminario_TI_20-11-2008.pdf >. Acesso em: 25 ago. 2014.

CEPIK, Marco; CANABARRO, Diego Rafael (Org.). Governança de TI: Transformando a Administração Pública no Brasil. Porto Alegre: WS, 2010.

CRUZ, Cláudio Silva da. Governança de TI e conformidade legal no setor público: um quadro referencial normativo para a contratação de serviços de TI. 2008. 252f. Dissertação (Mestrado em Gestão do Conhecimento e Tecnologia da Informação) Universidade Católica de Brasília, 2008. Disponível em: <http://portal2.tcu.gov.br/portal/pls/portal/ docs/2054320.PDF>. Acesso em: 7 jul. 2014.

DAWSON, Gregory S. et al. An examination of effective it governance in the public sector using the legal view of agency theory. Journal of Management Information System, v.33, n.4, p.1180-1208, 2016.

FERNANDES, Aguinaldo Aragon; ABREU, Vladimir Ferraz. Implantando a Governança de TI da estratégia à gestão dos processos e serviços. 3.ed. Rio de Janeiro: Brasport, 2012,
FRC - FINANCIAL REPORTING COUNCIL. The UK corporate governance code. 2014. Disponível em: <https://www.frc.org.uk/Our-Work/Publications/ Corporate-Governance/UK-Corporate-GovernanceCode-2014.pdf>. Acesso em: 19 ja. 2015.

HOOD, C. The new public management in the 1980s: Variations on a theme. Accounting, Organizations and Society, v.20, n.2-3, p.95-109, 1995.

Instituto Brasileiro de Governança Corporativa IBGC -. Código das Melhores Práticas de Governança Corporativa. 4.ed. São Paulo: IBGC, 2009.

\section{IOSDA - INSTITUTE OF DIRECTORS SOUTHERN} AFRICA. King III Report on Governance

Corporative. 2009. Disponível em: <http://www. iodsa.co.za/?kinglll>. Acesso em: 22 ago. 2014.

\section{ITGI - IT GOVERNANCE INSTITUTE. Board}

Briefing on IT Governance. 2007. Disponível em: >http://www.isaca.org/Knowledge-Center/ Research/ResearchDeliverables/Pages/BoardBriefing-on-IT-Governance-2nd-Edition.aspx>. Acesso em: 22 ago. 2014.

KORAC-KAKABADSE, Nada; KAKABADSE, Andrew. IS/IT Governance: Need for a integrated model. Corporate Governanace, v.1, Issue, 4, 2001. Disponível em: <http://www.emeraldinsight.com/ doi/pdfplus/10.1108/EUM0000000005974>. Acesso em: 22 ago. 2014.

MAHONEY, J. Briefing for IT Leaders: Tomorrow's Trends and Today Decisions. Gartner Management Review, v.46, p. 28, 2012.

MASSON, Eloisa Toffano Seidel et al. A Governança de TI autônoma na Administração Pública Federal. XI Simpósio de Excelência em Gestão e Tecnologia - SEGeT, 2014, Rio de Janeiro. Anais do XI SEGeT, 2014, Rio de Janeiro. 
MEDEIROS, Bruno Campelo et al. Maturidade da Governança de Tecnologia da Informação: diferenças entre organizações públicas brasileiras. Revista de Administração FACES Journal Belo Horizonte, v.15. n.2. p.81-99, abr-jun. 2016.

MOTA, Ariane Firmeza; MARQUES, Érico Veras. Governança da Tecnologia da Informação: um estudo bibliométrico no período de 2007 a 2012. IV EnADI, 2013, Bento Gonçalves-RS. Anais do IVI EnADI. Rio Grande do Sul: EnADI, 2013.

\section{OECD. Diretrizes da OCDE sobre governança corporativa para empresas de controle estatal. Disponível em: <http://www.oecd. org/daf/ca/corporategovernanceofstate- ownedenterprises/42524177.pdf>. Acesso em: 17 jan. 2015.}

OIKAWA, Rosemeire Araújo; CHAVES, Elisabete Cecília; GALEGALE, Napoleão Verardi. Importância e contribuições do plano diretor de TI no setor público. VIII Workshop de Pós-graduação e Pesquisa do Centro Paula Sousa. São Paulo, 9 e 10 out. 2013.

PEREIRA, Max Roberto. Gerenciamento de serviços em TI pelo modelo COBIT: livro digital / Max Roberto Pereira, Rudiney Marcos Herdt; design instrucional Delma Cristiane Morari. - Palhoça: Unisul Virtual, 2011. 281 p.: il.; $28 \mathrm{~cm}$.

RODRIGUES, José Geraldo Loureiro. Diretrizes para a implantação da governança de TI no setor público brasileiro à luz da teoria institucional.
2010, 170f. Dissertação (Mestrado em Gestão do Conhecimento e Tecnologia da Informação) - Universidade Católica de Brasília, 2010. Disponível em <http://www.bdtd.ucb.br/tede/ tde_busca/arquivo.php?codArquivo $=1242>$. Acesso em: 6. jul. 2014.

SANTOS, Diogo Finardi dos; PAULA, Liamar Mayer de. Alinhando a governança de TI com os negócios: um estudo entre COBIT e ITIL. Revista de Tecnologia Aplicada - RTA. v.5, n.3, p.16-26, set-dez. 2016.

SANTOS, Leonel Cerqueira; SANTOS JR., Carlos Denner dos. A Study on the impact of nonoperational mechanisms on the effectiveness of public information technology governance. Revista de Administração - RAUSP, São Paulo-SP, n.52, p.256-267, 2017;

WEBB, Phyl; POLLARD, Carol; RIDLEY, Gail. Attempting to define IT Governance: Wisdom or Folly? 39th Hawaii International Conference of Systems Sciences. IEEE Computer Society. 2006. Disponível em: <http://dl.acm.org/citation. cfm?id=1110022>. Acesso em: 22 ago. 2014

WEILL, Peter; ROSS, Jeanne W. IT Governance on one page. CISR/Sloan Working Papers, CISR working paper No. 349 and Sloan working paper No. 4516-04. Cambridge: Massachusetts Institute of Technology, 2006. Disponível em: <http:// materias.fi.uba.ar/7558/Lecturas/cisrwp349IT\%20Governance\%20on\%200ne\%20Page.pdf>. Acesso em: 10 ago. 2014. 
Recebido em: 15 de Agosto de 2017

Avaliado em: 14 de Setembro de 2017 Aceito em: 2 de Outubro de 2017
1 Possui graduação em Administração pela Universidade Federal de Sergi-

pe (2004) e Mestrado em Educação pela Universidade Federal de Sergipe (2010). Atualmente é Professor e Coordenador dos Cursos de Bacharelado em Administração e Tecnológico em RH da UNIT - Universidade Tiradentes. E-mail: jwsfilho20102@gmail.com 